\title{
Artist, Teacher, Scholar, Organizational Leader, Administrator, Collector: Art Educators' Beliefs About Roles and Status
}

\section{Thomas Ritenbaugh}

Within that larger field of general education which seeks to determine its own place in the scheme of things, the art educator remains an enigma. The role and status of the art educator remain somewhat of a conundrum to the public, the art world and general education. Even more surprisingly, the role and status of the art educator are elusive even among role occupants themselves.

\section{The Problem for Art Education}

Within the field of education, already uncertain about its own status, what is the status of the art educator? How do art educators perceive themselves, as artists or teachers? Do art educators feel that they occupy a unique position related to but different from both those fields? - Do art educators recognize an art education with roles beyond that of artist and teacher?

\section{Development of the Role of the Art Educator}

The history of the role of the art educator is revealing. If it is taken to combine the role of artist and teacher as separate but parallel within the same person, are educators may be perceived as artists who teach what they know about art from a personal history of art production. This view provides a long history of the role, one conceivably a segment of all social development.

The history of the role of the art educator differs somewhat, however, if the role of art educator is taken to represent the social invention of a role for educators to take on the responsibility for teaching "art" within the organization of the school. In this scenario, the role is a relatively modern one in American public schools, and parallel developments have also occurred internationally. The current art education profession is staffed by many in various settings and formats, but the connection between artists and pupils has endured.

For at least the past 40 years during which colleges and universities have assumed responsibility for pre-service art education, the primary model for the status of art educator has been the artist-teacher, a useful but conflictfilled combination. The respective roles of artist and teacher have very different focuses and require very different strengths. Nevertheless, many art educators have attempted to merge those roles, this perhaps in response to 
perceived personal or societal expectations. Writings in the field have tended to focus on these two roles within the art educator.

\section{The Roles of This Study}

One of the prevailing art education assumptions has been that art educators wish to be artists. After all, it is our connection with art that has brought most of us into the profession, and much has been written about us as Artist-Teachers (Arts, Education and Americans Panel, 1977), (Bittle, 1987), (Hammer, 1984), (Hayman, 1958), (LaDuke, 1978), (Lanier, 1959, 1961), (Logan, 1961), (Lowe, 1958), (McCracken, 1959), (Pelikan, 1934), (Raleigh, 1965), (Szekely, 1978), (Thompson, 1986), and (Wasserman, 1959).

This study suggests that there are other roles beyond that of artist and teacher which are essential in an increasingly large and complex profession. To an already extensive list of art education roles, other observers (Erickson, 1987) have suggested the existence of a requirement for additional roles specifically within the school setting: the art content expert; the art curriculum expert; the art instruction expert. All roles are increasingly essential in a culture as diverse and multifaceted as our own.

Seven roles were addressed in the study: Own (but unidentified) role, Administrator, Artist, Collector, Organizational Leader, Scholar and Teacher. Most, if not all, roles in art education could be clustered around these types.

\section{Some Dimensions of Role for Art Education}

It is conceivable that single art educators exemplify only a single role among the primary list of six. However, the greater likelihood is that multiple roles combine in each art educator to greater and lesser extents.

Much of art education theory proceeds from certain assumptions and expectations about the role of art educators. Chief among these is the professional expectation that certain roles (most especially the roles of artist and teacher) do combine within the art educator. Also assumed are the attitudes of art educators themselves toward this or other role combination in terms of beliefs about themselves, general beliefs, norms and goals.

However, these assumptions are generally without concrete substantiation. They represent a level of "folk knowledge." They may be founded in actual experience which has found its way into the collective understanding of the profession, but there are few data to support them. The rarity of sophisticated sociological research that describes and analyzes the values, norms, and roles of art educators related to the art and aesthetics of our society or the interrelatedness and interdependence of sub-groups inhibits our ability to understand ourselves and points to the need for this study. 


\section{Objectives of this Study}

The purpose of this study is to find out about art educators from two perspectives. The first perspective is to describe art educators themselves. The second perspective seeks to discover art educators' beliefs about their own and others' roles; beliefs about others in emphasized roles; degrees of attention given to each role; sources and evaluations of role satisfaction; the relative status of particular art education roles.

\section{Methodology}

In the fall of 1988,185 Pennsylvania art educators responded to a survey of beliefs about roles in art education designed originally to test the artist-teacher assumption but expanded to include at least four other major roles in the field. A majority of the participating sample were female $(63.2 \%)$, highly educated (65\% have at least a masters degree), experienced (more than $75 \%$ have been teaching at least 10 years), mature (nearly $60 \%$ are over 40 years old) and favorably disposed toward membership in the professional associations (66.5\% are currently members). Participants were divided among five levels of instruction typically used by the profession: elementary $(32.7 \%)$, secondary $(38.2 \%)$, higher education (14.5\%),

supervision/administration (12.1\%) and other (2.4\%), all ways to categorize those who participated in the study. Response rate for the study was $56.92 \%$.

Beliefs about the studied roles were divided into four cognitive orientation belief types. The belief types, Beliefs about self (internal/factual), General beliefs (external/factual), Norms (external/desirable) and Goals (internal/desirable) represent ways to (a) measure cognitive orientation toward the seven art education roles, (b) compare five standards of role involvement and rewards (role itself, esteem, prestige, role emphasis and role satisfaction) and (c) determine status rankings among art education roles.

\section{The Instrument}

The survey instrument consisted of 99 items, 34 about personal information and Own Role. The remainder of the items asked for participant responses to statements about described fictional art education role occupants.

Role

1. Administrator

2. Artist

3. Collector

4. Organizational leader

5. Scholar

6. Teacher
Fictional Name

(Zeus Foreman)

(Barbara Zahn)

(Marshall A. Cache)

(Stella Champion)

(Sage Savant)

(Ed Master) 
A Likert-type scale of graduated responses was used to allow a range of positive to negative responses. Statements relating to the fictional role models could receive any one of five responses: Strongly agree; Agree; Undecided; Disagree; Strongly disagree.

Responses represent degrees of concurrence or nonconcurrence. The order of the values on the Likert-type Scale was mixed to provide diversity and stimulation for respondents.

When responses are assigned values and are averaged, a "Cognitive Orientation" of 5 represents the highest or most positive orientation toward the major idea contained within the statement; 1 represents the lowest or most negative orientation. A cognitive orientation of 3 represents a neutral orientation. All averaged responses above a 3 represent increasingly positive orientations; those below 3 represent increasingly negative orientations.

\section{Data Analysis}

The data were examined in several ways. The first set of data is descriptive, creating a word picture of the sample participating in the research and generally expressed in raw numbers and percentages. Data are grouped according to Personal Information (age and sex of respondents), Professional Experience (number of years in art education and specific levels of art education, current instructional level), Educational Attainment and Professional Membership.

A second major set of data determine respondents' beliefs about their own role in art education. Even though the statements to which they responded are stated in cognitive orientation terms, the data are reported again in raw numbers and percentages.

The largest set of data deals with respondents' beliefs about six major roles in art education and contains six subsets of 10 statements each. Data are reported in terms of Cognitive Orientation.

\section{Cognitive Orientation}

The method of creating the types of questions asked in the instrument and for measuring beliefs about the various roles and aspects of roles is Cognitive Orientation (Kreitler and Kreitler, 1976) which is based on the theory that cognition, particularly through the orienting reflex, determines behavior. The Kreitlers have proposed that a structure of beliefs about self, general beliefs, norms and goals inclines individuals to behave in particular ways. They base their experiments on two hypotheses:

1. Human behavior above the level of spinal reflexes is controlled and directed by cognitive orientation, its contents and/or processes. 
2. Knowledge about specific cognitive orientations, their content, strength, and mode of functioning, makes possible predicting the ensuing molar behavior. This study, however, does not use the predictive aspect of cognitive orientation. Rather, it is used to create an inventory of art educators' beliefs about their own and other roles in art education.

\section{Sample Findings}

Although a multitude of role possibilities have emerged, all respondent groups indicated strongest identification with the Teacher role, the most satisfying, prestigious, estimable role in art education and the role which they most highly value and intend to retain. In response to the statement, "In my career in art education, one of my most important roles has been that of. ..." respondents indicated the following:

Teacher:

$95.2 \%$

Artist:

$38.4 \%$

Scholar:

$35.6 \%$

Administrator:

$31.3 \%$

Organizational Leader:

$26.5 \%$

Collector:

$17.8 \%$

Group respondents expressed little intention (Table 1) to acquire the other studied roles despite the numbers of individuals occupying and finding satisfaction in these roles.

Table 1: Unlike ( ), I Have No Intention of Ever Becoming a (Role).

\begin{tabular}{lrlllll}
\hline & ADMIN & ARTIST & COLLEC & ORGLDR & SCHOLR & TEACHR \\
Elementary & 2.0536 & 2.4821 & 2.7143 & 2.2857 & 2.4821 & 4.5000 \\
Secondary & 2.5323 & 3.1774 & 2.5161 & 2.7097 & 2.7377 & 4.4032 \\
Higher Ed & 2.6957 & 2.6250 & 3.0000 & 2.8261 & 3.7083 & 4.2917 \\
Supv/Admin & 4.4706 & 3.0526 & 3.0000 & 3.2000 & 3.4737 & 3.9444 \\
Male & 2.6774 & 3.2687 & 2.8788 & 2.7879 & 2.9848 & 4.2615 \\
Female & 2.5128 & 2.5652 & 2.5776 & 2.5517 & 2.8696 & 4.4569 \\
Mbr & 2.7417 & 2.7355 & .2 .6694 & 2.8361 & 3.0165 & 4.4250 \\
NMbr & 2.2203 & 3.0000 & 2.7213 & 2.2333 & 2.7000 & 4.4315 \\
TSAMPLE & 2.5698 & 2.8242 & 2.6868 & 2.6374 & 2.9116 & 4.3867 \\
& & & & & &
\end{tabular}

NOTE: n- 185. ADMIN - Administrator Role; ARTIST - Artist Role; COLLEC - Collector Role; ORGLDR - Organizational Leader Role; SCHOLR - Scholar Role; TEACHR - Teacher Role; Higher Ed - Higher Education; Supv/Admin - Supervision/Administration; Mbr - Member: NMbr - Non Member; TSAMPLE - Total Sample. 
Though they do not choose the other roles for themselves, respondents assigned a very high value to these other roles, (Table 2), viewing them as important to art education and their occupants as exemplars in those roles who bring great prestige to our field.

Table 2: It is Good for Art Education to Have Individuals Like ( ) Who Become Roles

\begin{tabular}{lcccccc}
\hline & ADMIN & ARTIST & COLLEC & ORGLDR & SCHOLR & TEACHR \\
Elementary & 4.0179 & 4.0357 & 3.9643 & 4.2679 & 4.1607 & 4.9286 \\
Secondary & 4.0806 & 4.2581 & 3.7097 & 4.3387 & 4.1452 & 4.8387 \\
Higher Ed & 4.0000 & 3.8333 & 3.9583 & 4.4167 & 4.5000 & 4.9167 \\
Supv/Admin & 4.2500 & 4.0000 & 4.0000 & 4.5000 & 4.3000 & 4.8000 \\
Male & 3.8060 & 3.9552 & 3.6716 & 4.1791 & 4.0149 & 4.7910 \\
Female & 4.1081 & 4.1121 & 3.9138 & 4.3966 & 4.3534 & 4.9052 \\
Mbr & 4.1148 & 4.0000 & 3.8361 & 4.4262 & 4.2951 & 4.8689 \\
NMbr & 3.9016 & 4.1639 & 3.8033 & 4.0984 & 4.0984 & 4.8525 \\
TSAMPLE & 4.0437 & 4.0546 & 3.8251 & 4.3170 & 4.2295 & 4.8634
\end{tabular}

NOTE: $n-185$. ADMIN - Administrator Role; ARTIST - Artist Role;. COLLEC - Collector Role; ORGLDR - Organizational Leader Role; SCHOLR - Scholar Role; TEACHR - Teacher Role; Higher Ed - Higher Education; Supv/Admin - Supervision/Administration; Mbr - Member; NMbr - Non Member; TSAMPLE - Total Sample.

Despite the professional value of these roles to art education, respondents know few art educators who would find as much satisfaction (Table 3) in any of those roles as they would in the role of Teacher. There is also positive orientation toward satisfaction in the Artist role.

Table 3: Most Art Educators That I Know Would Find Little Satisfaction in Being a (Role) Like ( ) Is.

\begin{tabular}{lrrrrrr}
\hline & ADMIN & ARTIST & COLLEC & ORGLDR & SCHOLR & TEACHR \\
Elementary & 2.4821 & 3.6429 & 3.1250 & 2.4464 & 2.4286 & 4.4286 \\
Secondary & 2.5806 & 3.7097 & 3.0484 & 2.7213 & 2.7581 & 4.4355 \\
Higher Ed & 1.9583 & 3.4583 & 3.0000 & 2.5417 & 2.5833 & 4.4583 \\
Supv/Admin & 2.6000 & 3.6000 & 3.3000 & 2.7500 & 2.4500 & 4.3500 \\
Male & 2.4328 & 3.4776 & 2.9403 & 2.7727 & 2.8209 & 4.3731 \\
Female & 2.4569 & 3.7328 & 3.1466 & 2.6000 & 2.5086 & 4.3966 \\
Mbr & 2.4344 & 3.6557 & 3.0410 & 2.7333 & 2.5164 & 4.3852 \\
NMbr & 2.4754 & 3.6066 & 3.1311 & 2.5246 & 2.8361 & 4.3934 \\
TSAMPLE & 2.4481 & 3.6393 & 3.0710 & 2.6630 & 2.6230 & 4.3888
\end{tabular}

NOTE: n- 185. ADMIN - Administrator Role; ARTIST - Artist Role: COLLEC - Collector Role; ORCLDR - Organizational Leader Role; SCHOLR - Scholar Role; TEACHR - Teacher Role; Higher Ed - Higher Education; Supv/Admin - Supervision/Administration; Mbr - Member; AMbr - Non Member; TSAMPLE - Total Sample.

Working Papers in Art Education 1989 - 1990 
Group respondents expressed satisfaction (Table 4) with their personal, internal art education role perspectives and a willingness to devote appropriate time and energy to maintain a high level of competence and satisfaction in their role(s). Relatively certain of personal satisfactions and goals, respondents perceived a variant view by art education peers (Table 5) who they judge somewhat less satisfied with their status.

Table 4: I Am Highly Satisfied With the Role(s) I Currently Play in Art Education

\begin{tabular}{|c|c|c|c|c|c|c|c|c|c|c|}
\hline & ALLn & ALL\& & EL8 & $\mathrm{SC} 8$ & $\mathrm{HE} 8$ & SA \& & M8 & $F_{8}^{8}$ & Mbr8 & NMBR \\
\hline Strongly agree & 55 & 29.7 & 18.2 & 22.2 & 45.8 & 55.0 & 36.4 & 26.5 & 31.7 & 25.9 \\
\hline Agree & 88 & 47.6 & 56.4 & 60.3 & 29.2 & 25.0 & 48.5 & 47.9 & 46.3 & 51.7 \\
\hline Undecided & 9 & 4.9 & 3.6 & 3.2 & 8.3 & 15.0 & 1.5 & 6.8 & 6.5 & 1.7 \\
\hline Disagree & 27 & 14.6 & 18.2 & 11.1 & 16.7 & 5.0 & 10.6 & 17.1 & 14.6 & 15.5 \\
\hline Strongly disagree & 4 & 2.2 & 3.6 & 3.2 & 0.0 & 0.0 & 3.0 & 1.7 & 0.8 & 5.2 \\
\hline Missing & 2 & 1.1 & & & & & & & & \\
\hline Cognitive Orientation & & 890 & & & & & & & & \\
\hline
\end{tabular}

Note: $\mathrm{n}=185$; EL - Elementary, SC - Secondary, HE - Higher Education, SA -

Supervision/Administration, M - Male, F - Female, Mbr - Member, NMbr - Non-Member (of professional art education association).

Table 5: As a Group Educators Who Play the Same Role(s) That I Do Aren't Very Content with Their Status

\begin{tabular}{|c|c|c|c|c|c|c|c|c|c|c|}
\hline & ALLn & ALL8 & EL\& & $\mathrm{SC} 8$ & $\mathrm{HE} 8$ & SA \& & M\& & $\mathrm{F}$ \& & Mbri & NMBR \\
\hline Strongly agree & 10 & 5.4 & 5.4 & 8.1 & 8.3 & 0.0 & 4.5 & 6.1 & 5.0 & 6.8 \\
\hline Agree & 47 & 25.4 & 30.4 & 24.2 & 16.7 & 25.0 & 25.4 & 26.1 & 24.0 & 28.8 \\
\hline Undecided & 55 & 29.7 & 32.1 & 27.4 & 29.2 & 35.0 & 32.8 & 28.7 & 29.8 & 32.2 \\
\hline Disagree & 63 & 34.1 & 28.6 & 38.7 & 41.7 & 25.0 & 34.3 & 34.8 & 35.5 & 32.2 \\
\hline Strongly disagree & 7 & 3.8 & 3.6 & 1.6 & 4. 2 & 15.0 & 3.0 & 4.3 & 5.8 & 0.0 \\
\hline Missing & 3 & 1.6 & & & & & & & & \\
\hline Cognitive Orientation & & 055 & & & & & & & & \\
\hline
\end{tabular}

Note: n - 185; EL - Elementary, SC - Secondary, HE - Higher Education, SA -

Supervision/Administration, M - Male, F - Female, Mbr - Member, NMbr - Non-Member (of professional art education association).

Despite personal role satisfaction and other-role approval, respondent groups sense that the esteem and prestige they desire for the profession from the general education community and from the community at large is minimal.

Working Papers in Art Education 1989 - 1990 


\section{Conclusion}

What is an art educator's role, and are we satisfied to be that role? The answer is that it is time for a new view of the role(s) of the art educator. A new view of the role(s) of the art educator calls for a closer examination of some of the common knowledge that is widely known in the art education profession. A half century of professional literature has suggested a narrow set of choices.

The evidence from this study indicates that art educators perceive and value a wide range of roles. However, respondents most highly value the role of Teacher for themselves, the role that satisfies and sustains them. It is the role they sought and the role they wish to keep. It is also important to note that art educators value other role occupants in our field and acknowledge that art education improves from the availability of individuals who become positive exemplars in any of the various other roles of art education.

\section{References}

Arts, Education and Americans Panel (1977). Coming to our senses. New York: McGraw-Hill, Inc.

Bittle, K. (1987). The teacher as artist. Schools Arts, 86 (6), 21-23.

Erickson, M. (1987, November). The roles of the art specialist in disciplinebased art education. Symposium of the Getty Center for Education in the Arts 1987-88 roundtable series, Roundtable I. Philadelphia, PA.

Hammer, B. (1984). The artist as teacher: Problems and experiments. Journal of Education, 166 (2), 181-187.

Hayman, D. (1958). John Cataldo artist-teacher. Art Education Bulletin, 15 (9), 2-3.

Kreitler, H. \& Kreitler, S. (1976). Cognitive orientation and behavior. New York: Spring Publishing Co.

LaDuke, B. (1978). Survival of the artist/teacher. Arts and Activities, 84 (2), 50-51.

Lanier, V. (1959). Affectation and art education. Art Education, 12 (7), 10, 21.

Lanier, V. (1961). Hyphenization takes command. Art Education, 14 (6). 5-8, 20-22.

Working Papers in Art Education 1989 - 1990 
Logan, F. W. (1961). Artist in the schoolroom: A modern dilemma. In E. W. Eisner \& D. W. Ecker (Eds.), Readings in art education (pp. 431-443). Waltham, MA: Blaisdell Publishing Company.

Lowe, R. (1958). The artist-as-teacher. Art Education, 6 (6), 10-11, 19.

McCracken, W. (1959). Artist-teacher. . . a symptom of growth in art education. Art Education, 12 (9), 4-5.

Pelikan, A. G. (1934). Teaching art as a profession. School Arts, 33 (5), 259-261.

Raleigh, H. P. (1965). The image of the art teacher. Art Education, 18 (7), 13-15.

Ritenbaugh, Thomas D. (1989). Artist, Teacher, Scholar, Organizational Leader, Administrator, Collector: Art Educators' Beliefs About Roles and Status. Unpublished doctoral dissertation, Pennsylvania State University, University Park, Pennsylvania.

Szekely, G. (1978). Uniting the roles of artist and teacher. Art Education, 31 (1). 17-20.

Thompson, K. (1986). Teachers as artists. Art Education, 39 (6), 47-52.

Wasserman, B. (1959). Image of the art teacher: a search for role and identity. Art Education Bulletin, 16 (8), 4-10. 